\title{
Research on Green Marketing Driving Force and Implementing Route Based on Innovation perspective
}

\author{
Feng WEI ${ }^{1, a,{ }^{\star}}$, Jun-Qiang ZHOU ${ }^{1, b}$ and Xiang REN ${ }^{1, c}$ \\ ${ }^{1}$ Guangxi University of Science and Technology, Liu Zhou, Guangxi, China \\ a372815127@qq.com, ${ }^{\text {a } q i a n g j u n z h o u @ 163 . c o m,{ }^{c} 651320598 @ q q . c o m}$ \\ ${ }^{*}$ Corresponding author
}

Key Words: Innovation Perspective; Green Marketing; Driving Force; Implementing Route

\begin{abstract}
As a key component to enhance competitiveness and gain sustainable advantage, innovation has become indispensable in the process of enterprise green marketing. The research analyzed factors that affect green marketing, considering that the government regulation, customer demand, enterprise abilities, technical level has huge influence on enterprise green marketing. Then, explored the driving force of green marketing based on innovation perspective, expected to find the implementing route for enterprise green marketing and offer reference for green marketing practices.
\end{abstract}

\section{Introduction}

For enterprises, innovation and marketing is the key to achieve sustainable. As a kind of marketing, green marketing emerges in the background of fragile ecological environment, gradually saturated market and intense competition. It combines green concept with marketing activities closely and provides a direction for enterprise to grabs a lasting competitive advantage. The practice of green marketing claims that enterprises should innovate so as to finally realize sustainable.

Most existing researches of green marketing are based on the background of developed countries that with mature market environment, without considering the dynamic instability in the transition period. Although china has established a relatively perfect market system, it is still in the stage of transformation, marketing activities are restricted by various factors. We all know that innovation is indispensable for enterprises to implement green marketing. So what will affect green marketing in the transformation period? What are the driving forces? How to implement? The article tries to adopt the theory of value chain and stakeholders explore the driving force and implementing route.

\section{Theoretical basis and research train of thought}

\section{Innovation theory and related content}

\begin{abstract}
"Innovation" was explained by Schumpeter in his monograph "economic development theory" earliest. He believes that innovation brings a new combination of production factors that haven't appeared into production system so as to make potential profits [1].After the1950s, along with the highlighting of science and technology, connotation of innovation expand to technical field. The OECD defined technological innovation as significant technological change including new products, new technology and process. In the 1990s, connotation of innovation broke the boundary of physical realm, expanded to the concept, process and other intangible aspects. Nigel Halpern defined innovation as the introduction of new things or new ideas, or the new ideas, products, processes and equipment that can be recognized by individual, organizations even the society [2].Although marketing innovation appears later, the statement of the relationship between marketing and innovation can be traced back to basic functions of the enterprise illustrated by Peter Drucker, "Marketing and innovation is the only two basic functions of the enterprise".
\end{abstract}

\section{The connotation and characteristics of green marketing}

Green marketing is management operations and activities that can identify, predict, and meet the 
green demand of customers and can bring profits for enterprise to realize the sustainable development [3]. It is not a way of enterprise inducing customer, it's a way that can realize enterprise profit and customer satisfaction at the same time promote the harmony between human and nature relying on green technology and green market[4]. Summarized the domestic and foreign scholars' view, green marketing can be defined as enterprises paying attention to environmental protection, reducing resource waste, finally realizing the sustainable development among the enterprise, the society and the environment in the production, sales, after-sales and the process of recycling. Green marketing is a further extension of traditional marketing. Compared with traditional marketing, green marketing has some notable features: Green nature, External nature, Systemic nature.

\section{Innovation in the application of green marketing}

The innovation can create value for enterprise and marketing can help enterprises to capture value. The complement of innovation and marketing can make the enterprise have a better market performance [5]. When it comes to innovation in the application of green marketing, firstly, green marketing is a kind of innovation compared with traditional marketing; Secondly, the driving force of implementing green marketing is still needs to innovate. Green marketing it is not just the simple revolution of concept, but also a profound change that involves the harmony among the interests of the enterprises, consumers and the environment [6]. As a breakthrough innovation, green marketing emphasize more on sustainable and pays more attention to social responsibility and social welfare.

\section{Corresponding revelation and the research mentality}

In the past decades, the marketing thought and practice focus more on the technical details of marketing, and pays more attention to innovation [7]. Practice shows that successful companies tend to be more flexible and innovative. Implementation of green marketing is inevitably influenced by technology, market, policy, and other factors. Firstly, participants impose impacts on pressure system, then conveys to dynamic system, finally act on performance. Return, performance of green marketing form a reverse feedback which will act on the participants, pressure system and power system.

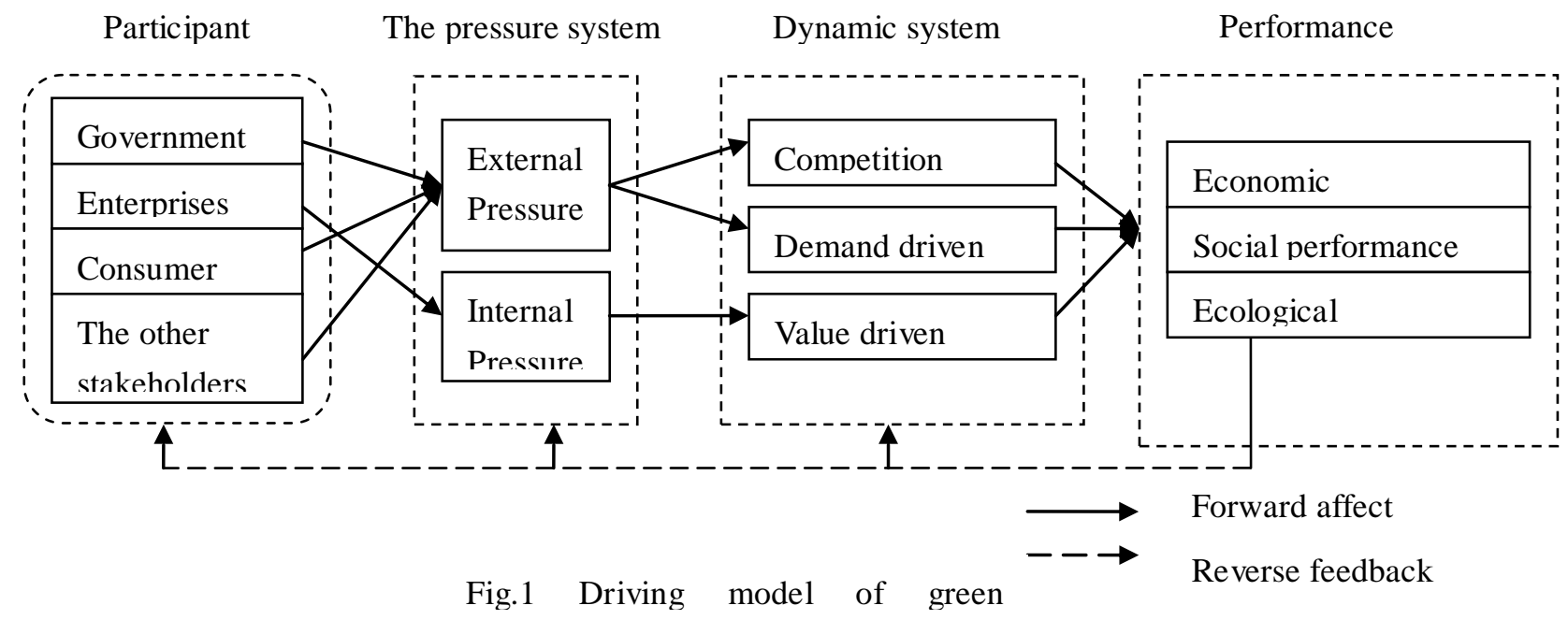

\section{The influence factors of enterprises implementing green marketing}

Now green sustainable development has become the consensus of business, and in the process of enterprise implementing green marketing, governments, customers and the community public and other stakeholders will have an effect on the marketing of enterprises. Then, we will analyze the influence factors of enterprises implementing green marketing from several aspects of government regulation, customer demand, enterprise ability, technical level and stakeholders.

\section{Government regulation}

The market mechanism is the most effective means to solve the problem of resource allocation. 
Similarly, the smooth implementation of green marketing also depends on the role of market mechanism. However, market mechanism is conditional, government regulation is necessary. Although enterprises are main participator of green marketing, implementation of green marketing relies on the attitude of government. Green marketing possesses external characteristic, products or services that provided in green marketing have some traits of public goods. As the representative of social interests, government has obligation to achieve sustainable of the economy and society. The government has the right of jurisdiction and sanctions and government's regulation constraints can provide a relatively fair environment for the enterprise.

Government intervention is mainly provides system or incentive "institutional arrangement", occasionally a mandatory administrative commands. For the moment, support and incentive policies of government are more important than other external factors under market mechanism [8]. For example, tax breaks, preferential loans and subsidies can effectively promote the enterprise green transition and create a good environment of development for the implementation of green marketing. And environmental protection laws and regulations, supervision and inspection issued by the government can effectively urge enterprises to abandon the traditional gray development mode.

\section{Customer requirements}

Classical economic theory believes that customers tend to maximize the interests of the individual with minimum cost. For customers, only if their demand were satisfied, their personal welfare reaches the maximum. With the awakening of green consciousness, people increasingly pay attention to green attributes of product. The connotation of green marketing is adapted to today's development and requirements, and it is the direct reaction to the green consumer behavior that contains "green, natural, healthy and harmonious"[9].There is no doubt that demand for green products has become an important push for enterprises to implement green marketing.

Although the customer's perception of green concept and green product is the foundation of green purchasing behavior, sometimes the customer demand of green products is not consistent with the buying behavior. In fact, only when the consumer considers that the purchase behavior can achieve the ecological improvement and meet its value orientation and the actual demand, the customer's green demand will convert into a real purchasing behavior [10]. Additional, different types of demands for green products have different motives. All in all, different consumer groups have different preference to the demand for the same green products. To some extent, green customer's different needs increased the uncertainty of enterprises to implement green marketing.

\section{Enterprise competence}

The implementation of green marketing is the business activities of enterprises as the standard, and it is restricted by their own conditions and capacity more. Green marketing requires enterprises to focus on environmental protection, energy saving and making full use of resources in the processes of development, design, production, sales and after-sales and recycle and so on. For enterprises, the technical requirements are higher, the implement risk is bigger. There is no doubt that the enterprise ability is particularly important at this time. Innovation ability and marketing ability are regarded as the significant support of enterprise competence. In the integration of enterprise resources, identifying innovative direction and promoting innovation have great significance. In addition, enterprises that have a high level marketing ability can better identify customer requirements and understand the factors that influence customers' choice [11].

\section{The dynamic analysis of green marketing under the innovation perspective}

\section{The driving competition of market}

The resources theory believes that competitive advantage root in internal value and it is difficult to be imitated. To achieve sustainable development, valuable and scarce resources must be paid [12].Green and competitiveness are complementary to each other; it is difficult to cater to the needs of sustainable if the enterprise is short of green competitiveness. For enterprises, ultimate goal of 
competition is to achieve sustainable. Fiercely competition has become the external pressure for enterprises to implement green marketing.

Philip Kotler pointed out that differentiation is the key to obtain competitive advantage, and innovation is an effective way to realize the differentiation in "marketing management". Green marketing can effectively help enterprises explore and maintain a competitive advantage based on differentiation and cost strategy. When enterprises realize that green marketing can improve enterprise's competitive advantage, it will carry out it imitatively. For enterprises, green marketing is not only a concept, but also a chance that can help enterprises make full use of resources, reduce negative impact in the fierce competition and shape the competitive advantage based on "green".

\section{The customer demand}

For enterprises, enterprise's success is to get better customer resources, and better meet customer needs than competitors. There is no doubt that customers' purchase or boycott will form pressure on businesses. As the most important business activities of the enterprise, the main task of marketing is to make clear understand of business and meet customer's needs. Modern marketing concept believes customer need is the starting point of marketing activities, the realization of guests' value and the satisfaction of need is the end of the marketing activities, as shown in Figure 2.

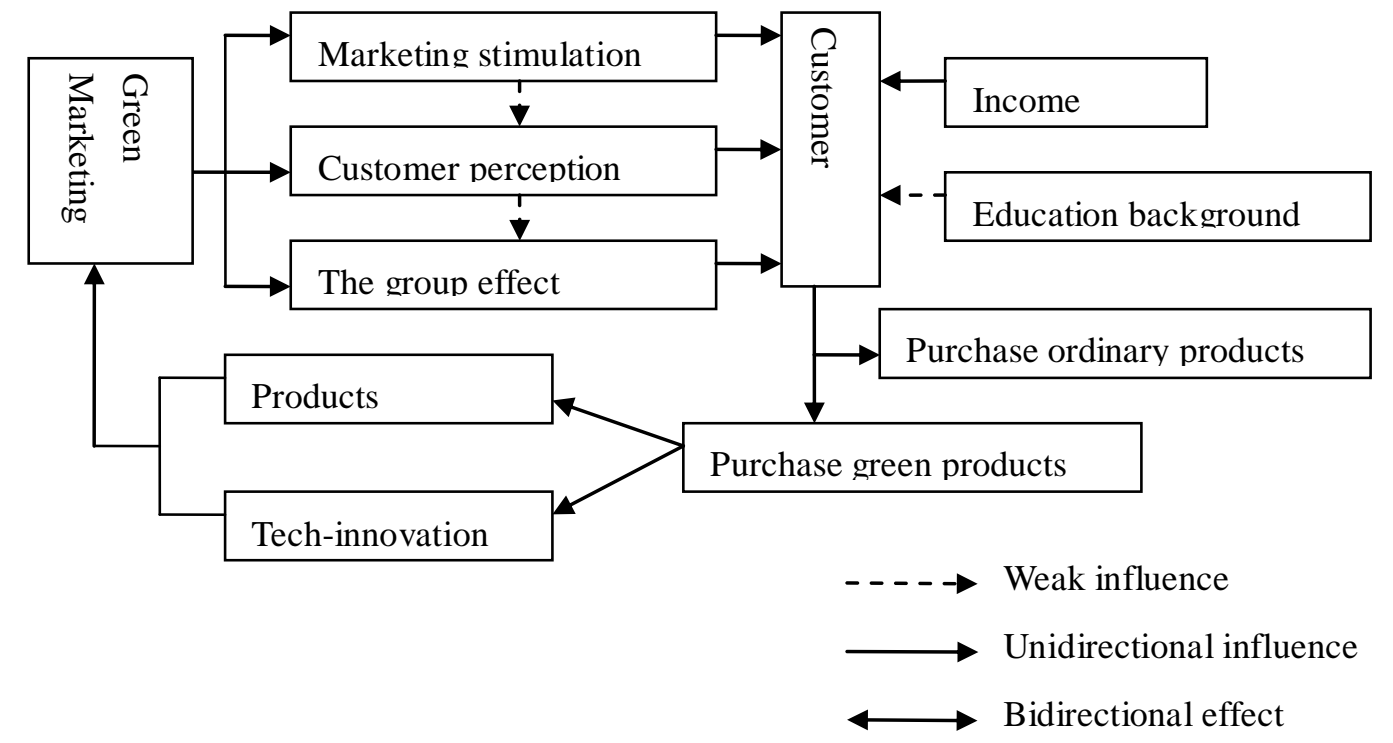

Fig.2 Schematic diagram of customer demand driven green marketing

According to "stimulus - response" theory of marketing, customer's purchase decisions are largely driven by marketing stimulation, perception and the group effect. The process of green marketing such as publicity, promotion and other marketing stimulation can stimulate customer's cognition, strengthen group effect and eventually stimulate purchasing behavior. Additional, income level significantly takes influence on demands and purchase behavior, education level also has a effect on green purchasing behavior. The customers that are rich and get educated often prefer pay a higher price for green products. With the improvement of people's living standard and awakening of green consciousness, customers prefer products with good environmental nature to satisfy their higher needs. Because of this, green demand gradually forms and provides power to support the implementation of green marketing for the enterprise.

\section{Enterprise value drivers}

The pursuit of profit or value maximization is the primary goal of the enterprise, Keynes's theory of "economic man" has already demonstrated that it is a mercenary nature for the enterprise. Only when green income that created through green marketing is greater than traditional income, the enterprise will carry out green marketing. Kumar's $3 \mathrm{vs}$ theory points out that value is the key of enterprise business activities, the realization of the value not only lies in the creation, but also lies on more efficient delivery. Nowadays, resource and environment has become the bottleneck that 
enterprise faces, environmental management has become urgently. Green marketing can effectively solve environmental problem, reduce costs. Additional, product pricing in green marketing has considered the value of environment compensation. However, for consumers that are sensitive to green products, the price of green products is higher but acceptable.

\section{Promote enterprises to implement green marketing based on innovative perspective}

\section{The construction of green network}

Implementing green marketing is a systemic engineering; it inevitably involves the upstream and downstream enterprises and cannot leave the coordination of the subsystems in the industry. In the process of promoting green marketing, a single enterprise's strength is limited after all, enterprises can build formal or informal contractual relationship with related enterprises through strengthening collaboration and establish green marketing network of strategic alliance, construct the system of green marketing network between enterprises and help enterprises to realize the resource sharing, complementary advantages and spread the risk. At the same time, the enterprise can build enterprise network marketing or distribution channel based on the Internet actively and reduce the cost of laying entity enterprise. In this process, the enterprise bring in IT and e-commerce talents and cooperate with large e-commerce operators, build perfect online network channels. In addition, in the process of network system construction the enterprise should achieve flat sales channel, enhance the consciousness of the channel members to the green degree.

\section{Customer service innovation}

Firstly, enterprises should set the concept that client satisfaction and strengthen customer relationship management so as to maximize customer value. Build effective customer response (ECR) system with manufacturers, wholesalers, adjust the direction of green product innovation timely, provide customers with better, faster product or service ultimately. Secondly, establish a timely communication system so as to realize communication between enterprises and customers. Finally, the enterprise should understand the market dynamics in a timely manner, develop green products market promotion plan and make full use of advertising, personal selling and public relations strategy in order to present to the customer a clear overall product information interface and improve enterprise product awareness in the public.

\section{Promote technology innovation}

Technology is one force that promotes enterprises to implement green marketing. Green technology is the precondition of the development of green product. Therefore, enterprises make full use of external resources to improve technology innovation ability so as to achieve the effect of $" 1+1>2$ ", such as bring in ISO14000 certification standard, pay attention to the use of green logo, be strict with material selection, process design and the final waste disposal. Within the enterprise, improve the training and learning mechanism, and create conditions to stimulate the innovation consciousness. In each link of product design and production of actively adopt and promote energy conservation and environmental protection technology, reduce energy consumption, reduce pollution to the environment destruction.

\section{Acknowledgment}

This research was financially supported by the following project:

The ministry of education humanities and social science research project (10YJA630162): Green supply chain and traditional manufacturing enterprise in green economic behavior research.

\section{References}

[1] Jin Chen, Gang Zheng, Innovation Management, Peking University Press, Peking, 2009, pp.24-26 
[2] Halpern Nigel, Marketing innovation: Sources, capabilities and consequences at airports in Europe's peripheral areas, Journal of airport management.16 (2010)52-58.

[3] Peattie Ken, Towards Sustainability: The Third Age of Green Marketing, The Marketing Review. 2(2001)129-146.

[4] Jifang Zheng, Green Marketing: Evolution, Conflict and Strategy Selection, China Soft Science Management. 4(2002)42-46.

[5] Aron O'Cass, Liem Viet, Winning through innovation and marketing: Lessons from Australia and Vietnam, Industrial Marketing Management.40 (2011)1319-1329.

[6] Qingwei Zhang, Development Strategy of Green Marketing in China during21centuery, Value engineering.5 (2010)52-54

[7] Zhu Q, Sarkis J, Green supply chain management pressures, practices and performance within the Chinese Automobile Industry, Journal of Cleaner production. 43(2007) 1041-1052.

[8] Jian Cao, XiaoboWu, and Gengui Zhou, The analysis of Green operating pattern of manufacturing enterprises evolution and the role of government, Science Research Management.1 (2013) 108-115.

[9] Saoping Jing, Study on the influence factors of word of mouth communication. The conversion of brand: Based on the perspective of green marketing, Management World.9 (2010)182-183.

[10] Saoping Jing, Yuhong Tao, The innovation route of product based on consumer demand perspective [J].Journal of Hebei University, 2013, 38(4):125-129.

[11] Jie Wu, Marketing capabilities, institutional development and performance of emerging market firms: A multinational study, International Journal of Research in Marketing.30 (2013) 36-45.

[12] Taiqiu Zhang, Jing Yang, and Jianjun Shi, Study on motivation and contingency factors in transition economy based on green strategy, Ecological Economy.6 (2012)28-33. 